\title{
Reductive coupling of carbonyl compounds promoted by cobalt or titanium nanoparticles
}

\author{
Fabiana Nador, Evangelina Mascaró, Melisa Castro, Cristian Vitale, and Gabriel Radivoy* \\ Departamento de Química, Instituto de Química del Sur (INQUISUR) CONICET-Universidad \\ Nacional del Sur, Avda. Alem 1253, 8000 Bahía Blanca, Argentina \\ E-mail: gradivoy@criba.edu.ar
}

Dedicated to Professor Manuel González Sierra on the occasion of his $65^{\text {th }}$ birthday

\begin{abstract}
The reaction of a series of aldehydes and ketones with readily prepared cobalt or titanium nanoparticles, under mild reaction conditions, led to the obtention of different reductive dimerization products depending on the nature of the transition metal used. Cobalt nanoparticles (CoNPs) allowed the selective transformation of the starting carbonyl compounds into vicinal diols, whereas the reaction promoted by titanium nanoparticles (TiNPs) led to the formation of the corresponding alkenes. In this last case, the use of trimethylsilyl chloride (TMSCl) as additive, at $0{ }^{\circ} \mathrm{C}$, also allowed the obtention of vicinal diols after acidic aqueous work-up.
\end{abstract}

Keywords: Carbonyl compounds, reductive coupling, cobalt, titanium, nanoparticles.

\section{Introduction}

Reductive coupling of carbonyl compounds is a versatile and powerful method for carbon-carbon bond formation, which is one of the main goals in synthetic organic chemistry. A variety of reagents have been used to perform this transformation leading to either vicinal diols or olefins, which are key compounds in the construction of highly functionalized skeletons found in many bioactive natural or synthetic products. ${ }^{1}$ Since the pioneering contributions in this field by Mukaiyama $^{2}$ and McMurry, ${ }^{3}$ the use of low-valent metals for the reductive dimerization of carbonyl compounds has evolved tremendously and gained widespread acceptance in the last decades. The pinacol coupling of aldehydes or ketones to give of 1,2-diols has been reported to promote successfully by many low-valent metal reagents, ${ }^{4}$ whereas for the reductive coupling/deoxygenation reaction, i.e. carbonyl coupling-olefination, low-valent titanium (LVT) reagents are by far the most widely utilized, ${ }^{1,5}$ mainly due the high oxophilicity and reducing 
power of the LVT reagents which facilitates the extrusion of oxygen from the titanium pinacolate intermediates to give the corresponding olefins.

On the other hand, the use of metal nanoparticles (NPs) in C-C bond forming reactions has received increasing attention in the last years. ${ }^{6}$ The unique catalytic properties of the metal NPs (2-10 $\mathrm{nm}$ in diameter) is assumed to be related to their high surface area and the possibility of charge distribution in electron transfer reactions. ${ }^{7}$ Although the specific role of these nanoparticles in the reaction mechanisms is not always easy to ascertain, it is known that the reactivity, reproducibility and stereochemistry of the reaction products are commonly affected by the method of preparation, the source of the metal, the reaction conditions, and the use of additives such as stabilizing agents. ${ }^{8}$ Reports in the literature about the use of metal NPs for the reductive dimerization of carbonyl compounds are scarce, very recently the use of supported gold NPs for the pinacol coupling of carbonyl compounds has been reported for the first time by Raffa and co-workers. ${ }^{9}$

In the last years our research work has been focused on the development of new methodologies for the reduction and coupling of organic compounds, based on the use of nonnoble metal-NPs (FeNPs, CuNPs, MnNPs, CoNPs) generated in situ from the corresponding commercially available metal(II) chlorides by reaction with lithium sand and a catalytic amount of an arene as electron carrier. This methodology allowed the preparation of very reactive, monodisperse spherical metal NPs with average sizes in the range of $3.5 \pm 1.5 \mathrm{~nm}$, which demonstrated to be very efficient in the reduction ${ }^{10}$ and coupling ${ }^{11}$ of a wide variety of organic compounds. It is worthy to note, that the above mentioned FeNP- or CuNP-based reactive systems efficiently promoted the reduction of aldehydes and ketones to give the corresponding

alcohols with excellent yield and stereoselectivity, ${ }^{10 a, d}$ but were unable to promote the reductive dimerization of the starting carbonyl compounds to give the corresponding olefin or pinacol products.

In this paper we want to present our results on the reductive coupling of carbonyl compounds promoted by CoNPs or TiNPs generated in situ from cobalt(II) chloride or titanium(IV) chloride, respectively, lithium sand and a catalytic amount of 4,4'-di-tertbutylbiphenyl (DTBB) as electron carrier. The simple and effective methodologies described herein allow the synthesis of vicinal diols or olefins depending on the nature of the metal-NPs used. To the best of our knowledge, this is the first report describing the use of CoNPs for the reductive dimerization of aldehydes or ketones.

\section{Results and Discussion}

\section{A. CoNP-promoted reductive coupling of carbonyl compounds. Synthesis of pinacols.}

A suspension of CoNPs was readily generated by reduction of anhydrous $\mathrm{CoCl}_{2}(1.0 \mathrm{mmol})$ with an excess of lithium sand (8:1 referred to $\left.\mathrm{CoCl}_{2}\right)$ and a catalytic amount of DTBB (15 mol \% referred to the cobalt salt) in THF as solvent and at room temperature. Droplets of this 
suspension analysed by transmission electron microscopy (TEM) showed well defined spherical nanoparticles with a particle size distribution of ca. $3.0 \pm 1.5 \mathrm{~nm}$ (Figure 1). Energy-dispersive $\mathrm{X}$-ray (EDX) analysis on various regions confirmed the presence of cobalt, with energy bands of 6.9 and $7.7 \mathrm{keV}$ (K lines).
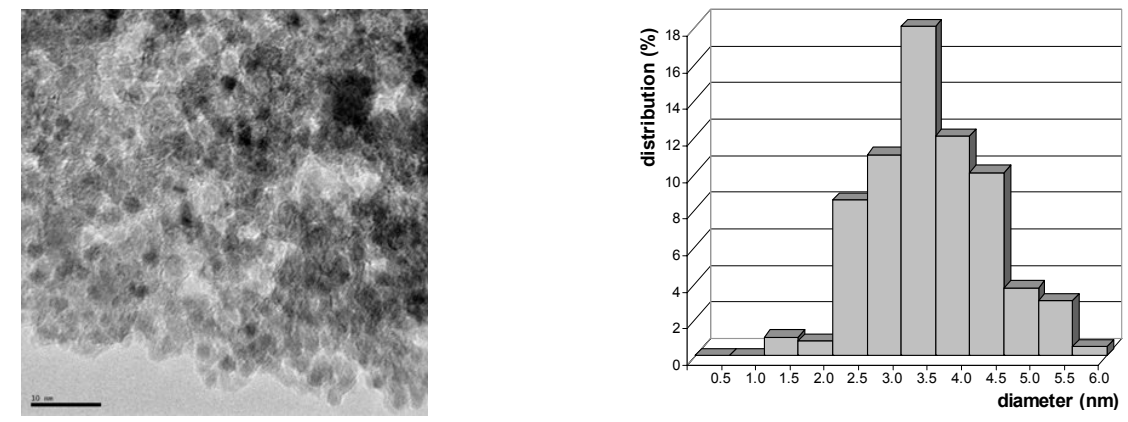

Figure 1. TEM micrograph and size distribution of the CoNPs. The sizes were determined for 100 nanoparticles selected at random.

Table 1 shows the results obtained in the reductive dimerization of carbonyl compounds promoted by CoNPs prepared in situ as described above. As shown in Scheme 1, the reaction of a series of aldehydes and ketones with the CoNPs suspension, at room temperature and under a $\mathrm{N}_{2}$ atmosphere, gave the corresponding 1,2-diols 2 in good yields along with variable amounts of the direct reduction products 3 .

Benzaldehyde 1a was used as model substrate in order to optimize the reaction conditions. Thus, we observed that the use of an equimolecular amount of CoNPs (1.0 equiv., referred to the starting carbonyl compound) was essential for the total conversion of 1a into the corresponding pinacol 2a as the major reaction product, in a $d l /$ meso diastereomeric ratio of 2:1 (Table 1, entry 1). The effect of varying the reaction temperature on the formation of the desired 1,2-diol was then studied. Thus, the reaction performed at the reflux temperature of the solvent $\left(66^{\circ} \mathrm{C}\right)$ resulted in lower yields of the pinacol coupling product, leading to the preferential formation of benzyl alcohol 3a ( $\mathrm{ca} .60 \%$ ), whereas the reaction conducted at $0{ }^{\circ} \mathrm{C}$ gave the coupling product 2a albeit with very low conversion ( $c a .15 \%$ ) of the starting benzaldehyde. Under the optimized conditions the reaction of substituted aromatic aldehydes was then tested. We observed that the reaction course was highly dependent on the electronic properties of the substituents attached to the aromatic ring. Those substrates bearing electron-withdrawing groups such as $p$ chlorobenzaldehyde 1b or $p$-trifluoromethylbenzaldehyde 1c, gave the corresponding pinacol products in good to excellent yields (Table 1, entries 2 and 3). On the other hand, aromatic aldehydes bearing electron-donating groups at the para position rendered the corresponding benzylic alcohols 3d and 3e (Table 1, entries 4 and 5), nevertheless 2,3-dimethoxybenzaldehyde 1f gave the pinacol coupling product $\mathbf{2 f}$ as the major reaction product (Table 1, entry 6). This difference in reactivity depending on the position of the electron-donating substituent attached to 
the aromatic ring could be ascribed, to some extent, to the formation of a chelate between the ortho-methoxy group, the carbonyl oxygen and the metal, a fact that has also been observed by other authors. ${ }^{12}$

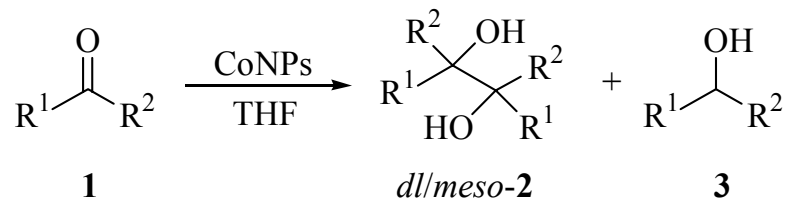

Scheme 1. Reductive coupling of carbonyl compounds promoted by CoNPs.

Table 1. Reductive coupling of carbonyl compounds promoted by CoNPs ${ }^{\mathrm{a}}$

\begin{tabular}{|c|c|c|c|c|}
\hline Entry & Starting carbonyl compound $\mathbf{1}$ & $\mathrm{t}(\mathrm{h})$ & $2(\text { Yield } \%)^{\mathrm{b}} d l /$ meso $^{\mathrm{c}}$ & $3(\text { Yield } \%)^{b}$ \\
\hline 1 & $1 \mathbf{a}$ & 12 & $\mathbf{2 a}(78) 70 / 30$ & $\mathbf{3 a}(20)$ \\
\hline 2 & 1b & 10 & 2b (76) $60 / 40$ & $\mathbf{3 b}(15)$ \\
\hline 3 & 1c & $10^{\mathrm{d}}$ & 2c $(80) 75 / 25$ & 3c (17) \\
\hline 4 & H 1d & 15 & $\mathbf{2 d}(12) \mathrm{ND}^{\mathrm{e}}$ & 3d (66) \\
\hline 5 & H 1e & 20 & $2 \mathrm{e}(8) \mathrm{ND}^{\mathrm{e}}$ & 3e (68) \\
\hline 6 & & 12 & $2 f(65) 60 / 40$ & $\mathbf{3 f}(30)$ \\
\hline 7 & $1 g$ & 10 & $2 g(87) 75 / 25$ & $\mathbf{3 g}(10)$ \\
\hline
\end{tabular}


Table 1. Continued

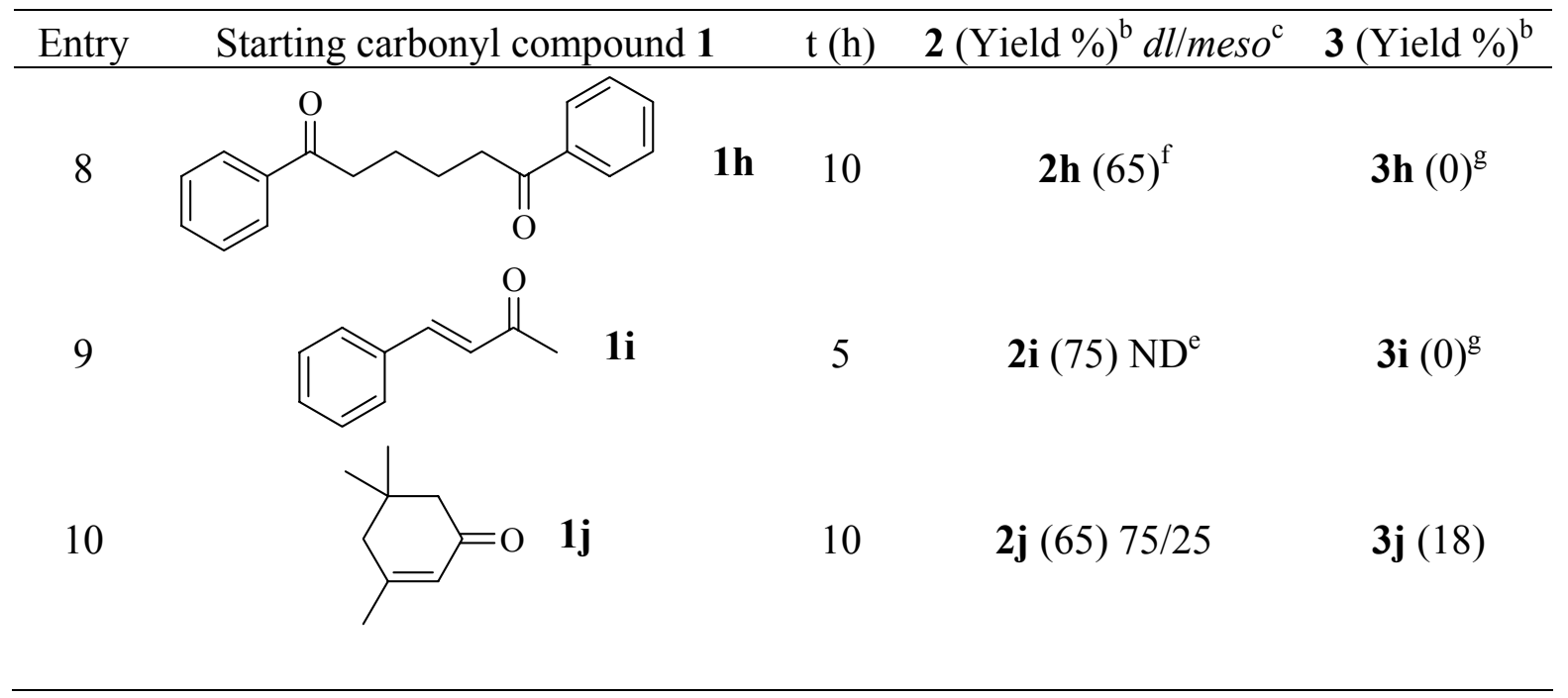

${ }^{a}$ Reaction conditions: $1(1.0 \mathrm{mmol})$, CoNPs $(1.0 \mathrm{mmol})$, in THF as solvent $(6 \mathrm{~mL})$, at $25{ }^{\circ} \mathrm{C}$ unless otherwise stated. ${ }^{b}$ Isolated yield after column chromatography (silica gel, hexane/ethyl acetate) based on the starting carbonyl compound 1. ${ }^{\mathrm{c}}$ Diastereomeric ratio determined by ${ }^{1} \mathrm{H}-$ NMR and/or GC-MS. ${ }^{d}$ Reaction conducted at the reflux temperature of the solvent $\left(66^{\circ} \mathrm{C}\right)$.

${ }^{\mathrm{e}}$ Diastereomeric ratio not determined. ${ }^{\mathrm{f}}$ The corresponding cis-1,2-diol was obtained almost exclusively. ${ }^{\mathrm{g}} 25 \%$ starting material recovered.

Under the same conditions, the reaction of acetophenone led to the corresponding pinacol product $\mathbf{2 g}$ in excellent yield (Table 1, entry 7). With this result in hand we tested the intramolecular pinacol coupling of the aromatic diketone $\mathbf{1 h}$, which led, almost exclusively to the cis-isomer of the cyclized 1,2-diol $\mathbf{2 h}$ in good yield (Table 1, entry 8). On the other hand, the reaction of aliphatic carbonyl compounds, such as decanal and 3-pentanone, resulted in low conversion of the starting material and low yields of the corresponding direct reduction alcohol products. Finally, $\alpha, \beta$-unsaturated ketones $\mathbf{1} \mathbf{i}$ and $\mathbf{1} \mathbf{j}$ (Table 1, entries 9 and 10) gave the corresponding vicinal diols 3,4-dimethyl-1,6-diphenyl-3,4-hexanediol $\mathbf{2 i}$ and 1-(1-hydroxy-3,3,5trimethylcyclohexyl)-3,3,5-trimethyl-1-cyclohexanol $\mathbf{2 j}$, respectively, in good yield, although the reductive coupling process was followed by subsequent reduction of the conjugated carboncarbon double bound. From the results described above it could be concluded that the CoNPspromoted pinacol coupling requires the presence of a carbonyl group conjugated with a pisystem to take place. With regard to the diastereoselectivity of the coupling process ( $d l$ vs. meso), as shown in Table 1, we found that the $d l$ product was favoured in all cases that we examined. The observed $d l$-diastereoselection could be interpreted by considering the mechanism generally admitted for the pinacol coupling promoted by low-valent metals. ${ }^{4 a, 12}$ As shown in Scheme 2, the first step could be assumed to be the formation of a cobalt-bound ketyl radical by electron transfer from the metal. When the ketyl radical attack is produced on a coordinated aldehyde, through a metal-bridged intermediate (Scheme 2, path A), the $d l$ product 
formation is favoured due to steric reasons; whereas if the dimerization of two such radicals takes place through a non-bridged intermediate, then the meso product predominates (Scheme 2, path B).
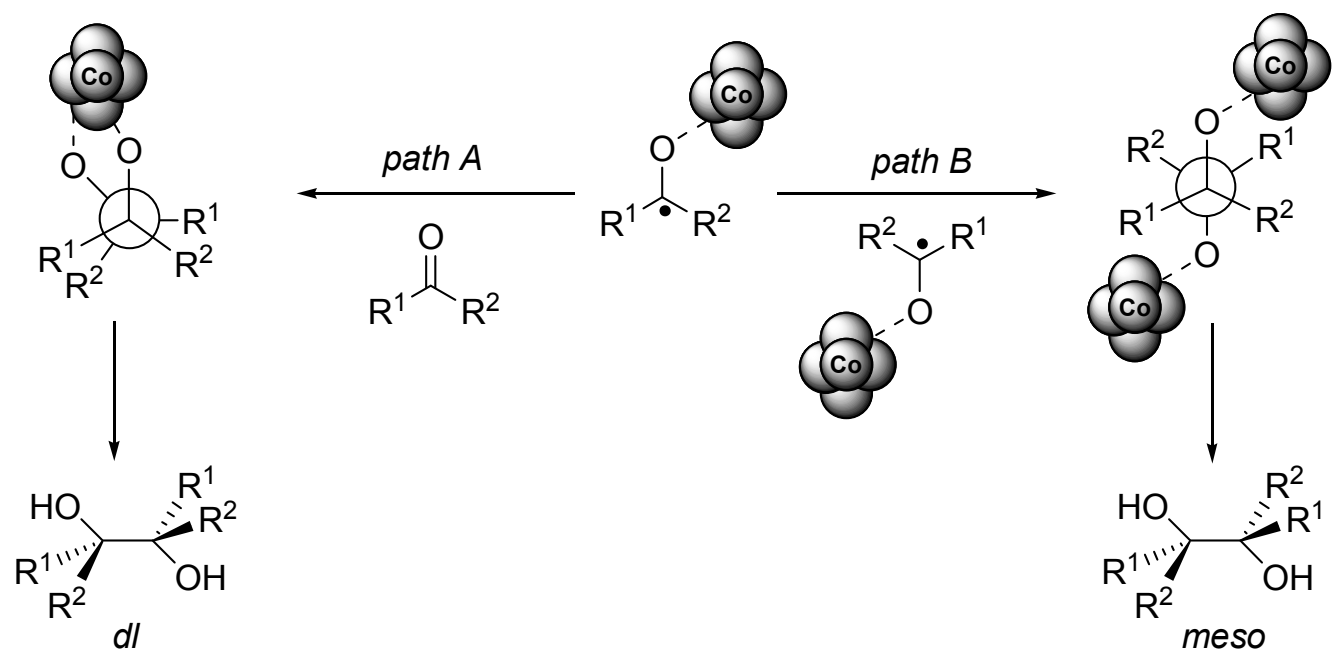

Scheme 2. General mechanism for the pinacol coupling reaction.

\section{B. TiNP-promoted reductive coupling of carbonyl compounds. Synthesis of olefins or pinacols.}

With the aim of performing a comparative study with the results obtained on the reductive coupling of carbonyl compounds promoted by CoNPs, we decided to test the performance of an analogous coupling system based on the use of in situ generated TiNPs. Thus, a suspension of the TiNPs was readily generated by reduction of anhydrous $\mathrm{TiCl}_{4}(3.0 \mathrm{mmol})$ with an excess of lithium sand (5:1 referred to $\left.\mathrm{TiCl}_{4}\right)$ and a catalytic amount of DTBB (7 mol \% referred to the titanium salt) in THF as solvent and at room temperature. Droplets of this suspension analysed by transmission electron microscopy (TEM) showed well defined spherical nanoparticles with a particle size distribution of ca. $8.5 \pm 2.5 \mathrm{~nm}$ (Figure 2). Energy-dispersive X-ray (EDX) analysis on various regions confirmed the presence of titanium, with energy bands of 4.5 and $4.9 \mathrm{keV}(\mathrm{K}$ lines).
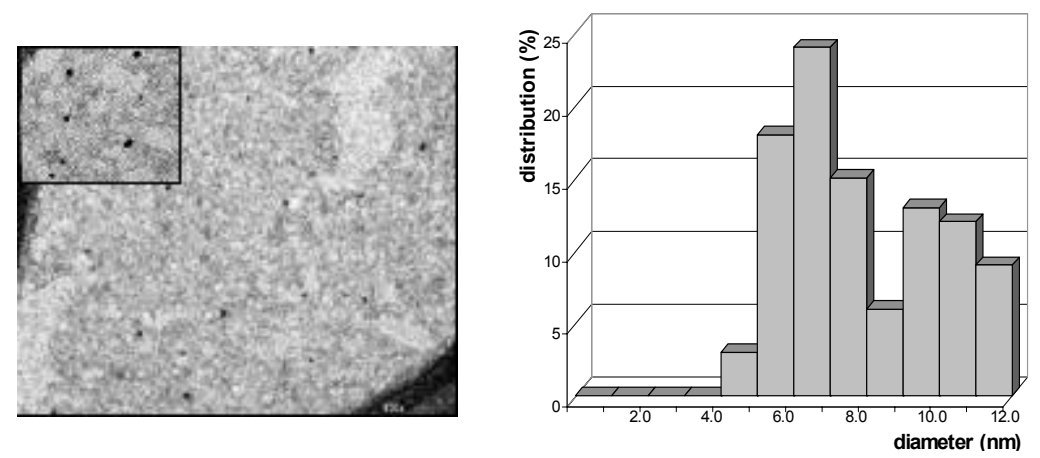

Figure 2. TEM micrograph and size distribution of the TiNPs. The sizes were determined for 100 nanoparticles selected at random. 
The results obtained in the reaction of a series of carbonyl compounds with an in situ prepared suspension of TiNPs are shown in Table 2. As expected, all the aldehydes and ketones tested led to the formation of the corresponding alkenes as the major coupling product (Scheme 3). Benzaldehyde 1a was again used as model substrate to find the optimal reaction conditions. Thus, we observed that the use of 3.0 equiv. of TiNPs (referred to the starting carbonyl compound) and heating at the reflux temperature of THF $\left(66^{\circ} \mathrm{C}\right)$, was necessary to obtain stilbene $\mathbf{4 a}$ in high yield and with excellent diastereoselectivity $(E: Z=99: 1)$.

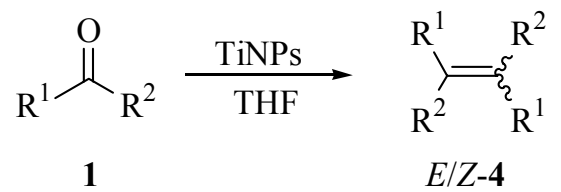

Scheme 3. Reductive coupling of carbonyl compounds promoted by TiNPs.

Table 2. Reductive coupling of carbonyl compounds promoted by TiNPs. ${ }^{\text {a }}$

\begin{tabular}{|c|c|c|c|}
\hline Entry & Starting carbonyl compound $\mathbf{1}$ & $\mathrm{t}(\mathrm{h})$ & $4(\text { Yield } \%)^{\mathrm{b}} E / Z^{\mathrm{c}}$ \\
\hline 1 & $1 \mathbf{a}$ & 6 & $4 \mathbf{a}(78) 99 / 1$ \\
\hline 2 & $1 \mathrm{~b}$ & 8 & $\mathbf{4 b}(70) 80 / 20$ \\
\hline 3 & $1 \mathrm{k}$ & 10 & $4 \mathbf{k}(75) 99 / 1$ \\
\hline 4 & 11 & 3 & 41 (85) 93/7 \\
\hline 5 & $1 g$ & 10 & $4 \mathbf{g}(84) 58 / 42$ \\
\hline 6 & $1 \mathrm{~m}$ & 12 & $4 \mathbf{m}(70) 75 / 25$ \\
\hline
\end{tabular}


Table 2. Continued

Entry Starting carbonyl compound $\mathbf{1}$ t

${ }^{a}$ Reaction conditions: $1(1.0 \mathrm{mmol})$, TiNPs $(3.0 \mathrm{mmol})$, in THF as solvent $(10 \mathrm{~mL})$, at $66{ }^{\circ} \mathrm{C}$ unless otherwise stated. ${ }^{b}$ Isolated yield after column chromatography (silica gel, hexane/ethyl

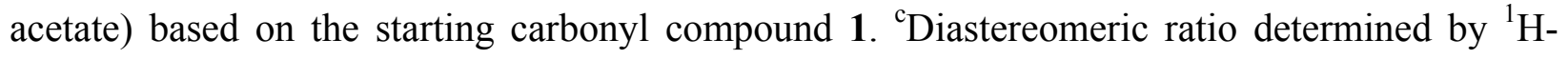
NMR and/or GC-MS.

The TiNPs-based coupling system showed to be effective in the reductive olefination of substituted aryl aldehydes, irrespective of the electronic properties of the substituents. As shown in Table 2 (entries 2 and 3) substrates bearing either electron-withdrawing or electron-donating groups attached to the aromatic ring (1) and $\mathbf{1 k}$, respectively) were coupled in good yield and with good to excellent $E / Z$ diastereoselectivity. The heteroaromatic aldehyde 2-furaldehyde 11, which shown to be inert in the presence of the CoNPs, gave (E)-1,2-di(2-furyl)-1-ethene $4 \mathbf{l}$ in good yield and with excellent diastereoselectivity (Table 2, entry 4). Aryl ketones such as acetophenone $1 \mathrm{~g}$ and 2-acetonaphthone $1 \mathrm{~m}$ gave the corresponding $E$-alkenes as the major reaction products in good yield (Table 2 , entries 5 and 6 ). The $\alpha, \beta$-unsaturated ketone 1i allowed the obtention of the triene $4 \mathbf{i}$ in good yield (Table 2, entry 7). Interestingly, under the same reaction conditions the diketones $\mathbf{1 h}$ and $\mathbf{1 n}$ were efficiently converted into the corresponding cyclic alkenes (Table 2, entries 8 and 9). On the other hand, aliphatic carbonyl compounds showed to be markedly less reactive. Decanal and 4-tert-butylcyclohexanone gave very low conversion ( $\mathrm{ca}$. 10\%) into the corresponding alkenes, and the highly hindered dicyclohexylketone did not react at all, even at longer reaction times. Among the aliphatic substrates tested, the best result was obtained with 5-nonanone 10 which gave the corresponding alkene 40 in $60 \%$ yield (Table 2, entry 10 ).

With the aim of extending the synthetic scope of this TiNP-based coupling system to the synthesis of vicinal diols, and based on the results reported by other authors on the use of chlorosilanes to promote the replacement of the alkoxide-metal bond with an alkoxide-silicon 
bond in the corresponding pinacolate intermediate, ${ }^{4 e}$ we decided to study the effect of the addition of trimethylsilyl chloride (TMSCl) to our TiNP-based coupling system (Scheme 4). As shown in Table 3, the reaction of different aryl-, vinyl- and alkyl carbonyl compounds with the TiNPs in the presence of 1 equiv. of TMSCl, after acidic aqueous workup, led to the formation of the corresponding vicinal diols as the main reaction products.

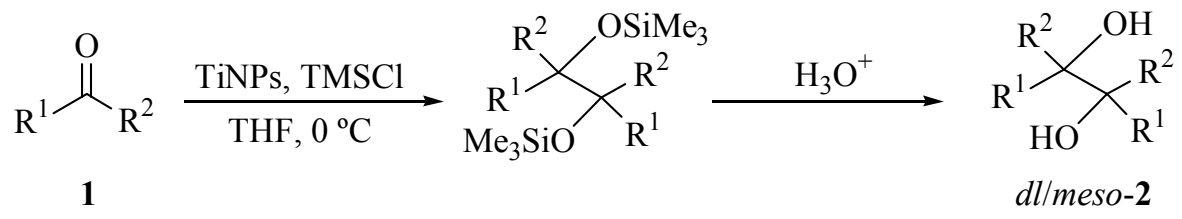

Scheme 4. Reductive coupling of carbonyl compounds promoted by TiNPs-TMSCl.

Table 3. Reductive coupling of carbonyl compounds promoted by TiNPs-TMSCl. ${ }^{\text {a }}$

\begin{tabular}{|c|c|c|c|}
\hline Entry & Starting carbonyl compound $\mathbf{1}$ & $\mathrm{t}(\mathrm{h})$ & $2(\text { Yield } \%)^{\mathrm{b}} d l /$ meso $^{\mathrm{c}}$ \\
\hline 1 & $1 \mathbf{a}$ & 4 & $\mathbf{2 a}(90) 72 / 28$ \\
\hline 2 & 1d & 6 & 2d (95) $75 / 25$ \\
\hline 3 & $1 \mathrm{~g}$ & 3 & $2 \mathbf{g}(70)^{\mathrm{d}} 70 / 30$ \\
\hline 4 & & 4 & $21(95) 60 / 40$ \\
\hline 5 & $\mathbf{1 i}$ & 4 & $\mathbf{2 i}(97) \mathrm{ND}^{\mathrm{e}}$ \\
\hline
\end{tabular}

${ }^{\mathrm{a}}$ Reaction conditions: 1 (1.0 mmol), TiNPs $(3.0 \mathrm{mmol})$, TMSCl $(1.0 \mathrm{mmol})$, in THF as solvent $(10 \mathrm{~mL})$, at $0{ }^{\circ} \mathrm{C}$. ${ }^{\mathrm{b}}$ Isolated yield after column chromatography (silica gel, hexane/ethyl acetate) based on the starting carbonyl compound 1 . ${ }^{\mathrm{c}}$ Diastereomeric ratio determined by ${ }^{1} \mathrm{H}-\mathrm{NMR}$ and/or GC-MS. ${ }^{\mathrm{d}} 20 \%$ starting material recovered. ${ }^{\mathrm{e}}$ Diastereomeric ratio not determined.

The reaction temperature showed significant influence on the reaction course, the optimal temperature being $0{ }^{\circ} \mathrm{C}$ in order to obtain maximum yields of the pinacol coupling products and avoiding the competitive olefination reaction. Under these conditions benzaldehyde 1a, $p$ methylbenzaldehyde 1d, 2-furaldehyde 11, acetophenone 1g and 4-phenyl-3-buten-2-one 1i gave 
the corresponding 1,2-diols in good to excellent yields and in short reaction times. The product ratio ( $d l$ vs. meso) observed using this TiNPs-TMSCl coupling system showed a diastereoselectivity in the same sense as that observed for the pinacol coupling reactions promoted by CoNPs, the $d l$ product being favoured in all cases that we examined. As was shown in Scheme 2, this could be explained through a ketyl radical attack on a metal-coordinated carbonyl compound, in this case followed by the replacement of the alkoxide-titanium bond by an alkoxide-silicon bond, leading to the corresponding vicinal diol after acidic aqueous workup. In conclusion, we have developed a simple and convenient methodology for the reductive coupling of carbonyl compounds, based on the use of in situ prepared cobalt or titanium nanoparticles, that allows the selective synthesis of vicinal diols or olefins, depending on the nature of the metal nanoparticles used. We are now studying other synthetic applications of this methodology and working on the development of a modified procedure for the reductive crosscoupling of carbonyl compounds.

\section{Experimental Section}

General. All moisture sensitive reactions were carried out under a nitrogen atmosphere. Anhydrous tetrahydrofuran was freshly distilled from sodium/benzophenone ketyl. Other solvents used were treated prior to use by standard methods. ${ }^{13}$ All starting materials were of the best available grade (Aldrich, Merck, Fluka) and were used without further purification. Commercially available $\mathrm{CoCl}_{2} \cdot 6 \mathrm{H}_{2} \mathrm{O}$ and $\mathrm{TiCl}_{4}$ were used for the coupling reactions. $\mathrm{CoCl}_{2} \cdot 6 \mathrm{H}_{2} \mathrm{O}$ was dried on oven $\left(2 \mathrm{~h}\right.$ at $\left.150^{\circ} \mathrm{C}\right)$ before use. Column chromatography was performed with Merck silica gel $60 \quad(0.040-0.063 \mu \mathrm{m}, 240-400$ mesh). Thin layer chromatography (TLC) was performed on precoated silica gel plates (Merck 60, F254, 0.25 $\mathrm{mm}$ ). Nuclear magnetic resonance (NMR) spectra were recorded on a Bruker ARX-300 spectrophotometer using $\mathrm{CDCl}_{3}$ (unless otherwise stated) as solvent and tetramethylsilane (TMS) as internal reference. Mass spectra (EI) were obtained at $70 \mathrm{eV}$ on a Hewlett Packard HP-5890 GC/MS instrument equipped with a HP-5972 selective mass detector. The purity of volatile compounds and the chromatographic analyses (GC) were determined with a Shimadzu GC-9A instrument equipped with a flame-ionization detector and a $2 \mathrm{~m}$ column $\left(1.5 \%\right.$ OV17 $9_{\mathrm{A}}$ SUS Chrom 103 80/1000), using nitrogen as carrier gas. TEM images of cobalt and manganese nanoparticles were recorded at the TEM service of the University of Alicante (Spain) using a Jeol JEM2010 microscope equipped with a lanthanum hexaboride filament and operated at an acceleration voltage of $200 \mathrm{kV}$. All the starting carbonyl compounds, included in Tables 1-3, were purchased form commercial sources (Aldrich, Fluka, Merck), and used as received. 


\section{Synthesis of 1,6-diphenyl-1,6-hexanedione (1h) and 1,9-decadiene-3,8-dione (1n). General procedure $^{14}$}

In a round bottom two necked flask, equipped with magnetic stirrer, dropping funnel and reflux condenser, magnesium turnings $(146 \mathrm{mg}, 6.0 \mathrm{mmol}$ ) and a cristal of iodine were placed under nitrogen atmosphere. The magnesium was activated by iodine sublimation. After cooling the flask, dry diethyl ether $(2 \mathrm{~mL})$ and drops of the corresponding aryl or alkyl halide (neat) were added. Then, the reaction mixture was vigorously stirred and the corresponding halide (5.0 $\mathrm{mmol})$ or dihalide $(2.5 \mathrm{mmol})$ in diethyl ether $(5 \mathrm{~mL})$ was slowly added through the dropping funnel at such a rate that the ether refluxes gently. After $2 \mathrm{~h}$ of heating at the reflux temperature of the solvent, the reaction mixture was cooled to $0^{\circ} \mathrm{C}$. Then, the corresponding carbonyl compound (1.5:1 ratio referred to the halide) was added and the mixture vigorously stirred until the reaction was completed (TLC). The reaction mixture was transferred to another flask containing finely crushed ice and was vigorously stirred. Twice the theoretical quantity of $30 \%$ $\mathrm{H}_{2} \mathrm{SO}_{4}$ was added to dissolve the formed $\mathrm{Mg}(\mathrm{OH})_{2}$. The aqueous layer was washed with diethyl ether $(3 \times 15 \mathrm{~mL})$ and the combined extracts were dried over anhydrous $\mathrm{Na}_{2} \mathrm{SO}_{4}$ and evaporated (20 mbar). The resulting residue was purified by flash column chromatography (silica gel, hexane-ethyl acetate) to give the corresponding alcohol. In order to obtain the corresponding carbonyl compounds, pyridinium dichromate (PDC, $1.03 \mathrm{~g}, 2.71 \mathrm{mmol}$ ) was added to a solution of the purified alcohol $(1.0 \mathrm{mmol})$ in $\mathrm{CH}_{2} \mathrm{Cl}_{2}(20 \mathrm{~mL})$. The mixture was stirred at room temperature until the reaction was completed (TLC) and filtered through celite pad. The filtrate was dried $\left(\mathrm{Na}_{2} \mathrm{SO}_{4}\right)$ and concentrated in vacuo $(20 \mathrm{mbar})$. The crude residue was purified by flash column chromatography (silica gel, hexane-ethyl acetate) to give the corresponding carbonyl compounds, $\mathbf{1 h}(57 \%)$ and $\mathbf{1 n}(54 \%)$.

\section{Representative procedure for the reductive coupling of carbonyl compounds promoted by CoNPs. Synthesis of vicinal diols}

A mixture of lithium sand (56 mg, $8.0 \mathrm{mmol})$, DTBB (40 mg, $0.15 \mathrm{mmol})$ and $\mathrm{CoCl}_{2}(130 \mathrm{mg}$, $1.0 \mathrm{mmol})$ in THF $(4 \mathrm{~mL})$ was stirred at room temperature under nitrogen atmosphere. The reaction mixture, which was initially dark green, changed to black, indicating the formation of the cobalt nanoparticles (CoNPs). Then, benzaldehyde 1a $(106 \mathrm{mg}, 0.101 \mathrm{~mL}, 1.0 \mathrm{mmol})$ in THF $(2 \mathrm{~mL}$ ) was slowly added by syringe. After total conversion of the starting material (TLC, GC), the resulting suspension was diluted with diethyl ether $(10 \mathrm{~mL})$ and treated with $10 \% \mathrm{HCl}(3 \times 10$ $\mathrm{mL}$ ). The combined extracts were dried over anhydrous $\mathrm{Na}_{2} \mathrm{SO}_{4}$, and evaporated (20 mbar). The resulting residue was purified by flash column chromatography (silica gel, hexane-ethyl acetate) to give the corresponding pinacol 2a (78\%). Isolated yields for compounds $\mathbf{2}$ are given in Table 1. The following known compounds included in Table 1 were characterised by comparison of their chromatographic and spectroscopic data $\left({ }^{1} \mathrm{H},{ }^{13} \mathrm{C}\right.$ NMR, and MS) with those described in the literature: 1,6-diphenyl-1,6-hexanedione $\mathbf{1 h},{ }^{15}$ 1,9-decadiene-3,8-dione $\mathbf{1 n},{ }^{16}$ 1,2-diphenyl1,2-ethanediol 2aa, ${ }^{17}$ 1,2-di(4-chlorophenyl)-1,2-ethanediol $\mathbf{2 b},{ }^{17}$ 1,2-di(4-trifuoromethylphenyl)1,2-ethanediol $\mathbf{2 c},{ }^{18}$ 2,3-diphenyl-2,3-butanediol $\mathbf{2 g},{ }^{17}$ 1,2-diphenyl-1,2-ciclohexanediol $\mathbf{2 h},{ }^{19 a}$ 
3,4-dimethyl-1,6-diphenyl-3,4-hexanediol $2 \mathbf{i}^{20}$ For new compounds, physical and spectroscopic data follow.

1,2-di(2,3-dimethoxyphenyl)-1,2-ethanediol (2f). Orange oil; $R_{f}$ (hexane/ethyl acetate 5/5) = 0.20; v (film) 3615-3141 (OH), $3079(=\mathrm{CH}), 1100(\mathrm{CO}), 756 \mathrm{~cm}^{-1}(=\mathrm{CH}) ; \delta_{\mathrm{H}}(300 \mathrm{MHz}) 3.72$ $(2 \mathrm{H}, \mathrm{s}, 2 \times \mathrm{OH}), 3.77\left(6 \mathrm{H}, \mathrm{s}, 2 \times \mathrm{OCH}_{3}\right), 3.81\left(6 \mathrm{H}, \mathrm{s}, 2 \times \mathrm{OCH}_{3}\right), 5.11(\mathrm{dl}, 2 \mathrm{H}, \mathrm{s}, 2 \times \mathrm{CHOH}), 5.17$ (meso, $2 \mathrm{H}, \mathrm{s}, 2 \times \mathrm{CHOH}), 6.75-7.02(6 \mathrm{H}, \mathrm{m}, 6 \times \mathrm{ArCH}) ; \delta_{\mathrm{C}}(75 \mathrm{MHz}) 55.5\left(2 \times \mathrm{OCH}_{3}\right), 55.6$ $\left(2 \times \mathrm{OCH}_{3}\right), 60.5\left(2 \times \mathrm{OCH}_{3}\right), 60.6\left(2 \times \mathrm{OCH}_{3}\right), 73.0$ (meso, $\left.2 \times \mathrm{CHOH}\right), 73.1(\mathrm{dl}, 2 \times \mathrm{CHOH}), 111.7$ $(2 \times \mathrm{ArCH}), 111.9(2 \times \mathrm{ArCH}), 120.0(2 \times \mathrm{ArCH}), 120.3(2 \times \mathrm{ArCH}), 123.5(2 \times \mathrm{ArCH}), 123.8$ $(2 \times \mathrm{ArCH}), 134.1(2 \times \mathrm{ArC}), 134.4(2 \times \mathrm{ArC}), 146.4(2 \times \mathrm{ArC}), 146.6(2 \times \mathrm{ArC}), 152.0(2 \times \mathrm{ArC})$, 152.2 (2×ArC); m/z $334\left(\mathrm{M}^{+}, 0.01 \%\right), 224$ (8), 210 (16), 209 (100), 194 (10), 193 (12); Anal. Calcd for $\mathrm{C}_{18} \mathrm{H}_{22} \mathrm{O}_{6}$ : C, 64.66; H, 6.63. Found: C, 64.74; H, 6.61.

1-(1-hydroxy-3,3,5-trimethylcyclohexyl)-3,3,5-trimethyl-1-cyclohexanol (2j). White solid; $\mathrm{mp} 48-50^{\circ} \mathrm{C} ; R_{f}$ (hexane/ethyl acetate 8/2) =0.14; v (KBr) 3692-3027 (OH), $1388\left(\mathrm{CH}_{3}\right), 1183$ $\mathrm{cm}^{-1}(\mathrm{CO}) ; \delta_{\mathrm{H}}(300 \mathrm{MHz}) 1.03-1.12\left[22 \mathrm{H}, \mathrm{m}, 6 \times \mathrm{CH}_{3}, 2 \times \mathrm{CH}\left(\mathrm{CH}_{3}\right) \mathrm{CH}_{2} \mathrm{C}\left(\mathrm{CH}_{3}\right)_{2}\right], 1.70-1.79(8 \mathrm{H}$, $\left.\mathrm{m}, 4 \times \mathrm{CH}_{2}\right), 2.03-2.10\left(2 \mathrm{H}, \mathrm{m}, 2 \times \mathrm{CHCH}_{3}\right) ; \delta_{\mathrm{C}}(75 \mathrm{MHz}) 22.7\left(2 \times \mathrm{CH}_{3}\right), 29.6(2 \times \mathrm{CH}), 34.1$ $\left[2 \times C\left(\mathrm{CH}_{3}\right)\right], 34.3\left(4 \times \mathrm{CH}_{3}\right), 43.3\left(2 \times \mathrm{CH}_{2}\right), 46.2\left(2 \times \mathrm{CH}_{2}\right), 52.8\left(2 \times \mathrm{CH}_{2}\right), 78.8(\mathrm{COH}) ; m / z 282$ $\left(\mathrm{M}^{+}, 0.002 \%\right), 140$ (17), 139 (96), 125 (38), 97 (11), 83 (50), 81 (13), 69 (30), 67 (13), 56 (27), 55 (100), 53 (12); Anal. Calcd for $\mathrm{C}_{18} \mathrm{H}_{34} \mathrm{O}_{2}$ : C, 76.64; H, 12.13. Found: C, 76.71; H, 12.09.

\section{Representative procedure for the reductive coupling of carbonyl compounds promoted by} TiNPs. Synthesis of olefins

To a vigorously stirred solution of $\mathrm{TiCl}_{4}(569 \mathrm{mg}, 0.329 \mathrm{~mL}, 3.0 \mathrm{mmol})$ in THF $(2 \mathrm{~mL})$, under nitrogen atmosphere, lithium sand (98 mg, $14.0 \mathrm{mmol}$ ) and DTBB (52 mg, $0.20 \mathrm{mmol}$ ) were added. The reaction mixture, which was initially dark green, changed to black, indicating the formation of the titanium nanoparticles (TiNPs). The reaction flask was introduced into a preheated silicon oil bath, at a temperature high enough to ensure the reflux of the solvent, and benzaldehyde 1a (106 mg, $0.101 \mathrm{~mL}, 1.0 \mathrm{mmol})$ in THF $(2 \mathrm{~mL})$ was slowly added by syringe. After total conversion of the starting material (TLC, GC), the resulting suspension was diluted with diethyl ether $(10 \mathrm{~mL})$, treated with $10 \% \mathrm{HCl}(10 \mathrm{~mL})$, and the aqueous layer extracted with diethyl ether $(3 \times 10 \mathrm{~mL})$. The combined organic extracts were dried over anhydrous $\mathrm{Na}_{2} \mathrm{SO}_{4}$, and evaporated (20 mbar). The resulting residue was purified by flash column chromatography (silica gel, hexane-ethyl acetate) to give the stilbene $\mathbf{4 a}$ (78\%). Isolated yields for compounds 4 are given in Table 2. The following known compounds included in Table 2 were characterised by comparison of their chromatographic and spectroscopic data $\left({ }^{1} \mathrm{H},{ }^{13} \mathrm{C}\right.$ NMR, and MS $)$ with those described in the literature: 1,2-diphenyl-1-ethene $\mathbf{4 a},{ }^{19}$ 1,2-di(4-chlorophenyl)-1-ethene $\mathbf{4 b},{ }^{21} 1,2$ bis-[4-(dimethylamino)phenyl]ethene $\mathbf{4 k},{ }^{22}$ 1,2-di(2-furyl)-1-ethene $\mathbf{4 1},{ }^{23}$ 2,3-diphenyl-2-butene $\mathbf{4 g}{ }^{24}$ 2,3-di(2-naphthyl)-2-butene $\mathbf{4 m},{ }^{21}$ 3,4-dimethyl-1,6-diphenyl-1,3,5-hexatriene $\mathbf{4 i},{ }^{25} 1,2$ diphenyl-1-cyclohexene $\mathbf{4 h},{ }^{26} 1,2$-divinyl-1-cyclohexene $4 \mathbf{n},{ }^{27}$ 5,6-dibutyl-5-decene $4 \mathbf{0}{ }^{28}$ 


\section{Representative procedure for the reductive coupling of carbonyl compounds promoted by} TiNPs-TMSCl. Synthesis of vicinal diols

To a vigorously stirred solution of $\mathrm{TiCl}_{4}(569 \mathrm{mg}, 0.329 \mathrm{~mL}, 3.0 \mathrm{mmol})$ in $\mathrm{THF}(2 \mathrm{~mL})$, under nitrogen atmosphere, lithium sand (98 mg, $14.0 \mathrm{mmol})$ and DTBB (52 $\mathrm{mg}, 0.20 \mathrm{mmol}$ ) were added. The reaction mixture, which was initially dark green, changed to black, indicating the formation of the titanium nanoparticles (TiNPs). The reaction flask was introduced into a prehetaed silicon oil bath, at a temperature high enough to ensure the reflux of the solvent. After stirring at this temperature for $2 \mathrm{~h}$ the reaction mixture was cooled to $0{ }^{\circ} \mathrm{C}$. Benzaldehyde (1a) $(106 \mathrm{mg}, 0.101 \mathrm{~mL}, 1.0 \mathrm{mmol})$ in THF $(2 \mathrm{~mL})$ was then added followed by the addition of trimethylsilyl chloride $(0.128 \mathrm{~mL}, 1 \mathrm{mmol})$. After total conversion of the starting material (TLC, $\mathrm{GC}), 1 \mathrm{M} \mathrm{HCl}(5 \mathrm{~mL})$ was added and the suspension was stirred at room temperature for $3 \mathrm{~h}$. The resulting mixture was extracted with diethyl ether $(3 \times 10 \mathrm{~mL})$. The combined extracts were dried over anhydrous $\mathrm{Na}_{2} \mathrm{SO}_{4}$, and evaporated (20 mbar). The resulting residue was purified by flash column chromatography (silica gel, hexane-ethyl acetate) to give pure diol $\mathbf{2 a}(90 \%)$. Isolated yields for compounds $\mathbf{2}$ are given in Table 3. The following known compounds included in Table 3 were characterised by comparison of their chromatographic and spectroscopic data $\left({ }^{1} \mathrm{H},{ }^{13} \mathrm{C}\right.$ NMR, and MS) with those described in the literature: 1,2-diphenyl-1,2-ethanediol $\mathbf{2 a},{ }^{17}$ 1,2-di(4methylphenyl)-1,2-ethanediol $\mathbf{2 d},{ }^{17} \quad$ 2,3-diphenyl-2,3-butanediol $\quad \mathbf{2 g}{ }^{17} \quad$ 1,2-di(2-furyl)-1,2ethanediol $\mathbf{2 l},{ }^{29}$ 3,4-dimethyl-1,6-diphenyl-1,5-hexadiene-3,4-diol $\mathbf{2} \mathbf{i}^{20}$

\section{Acknowledgements}

We are grateful for partial support provided by the CONICET (Project PIP 5104) and SGCyTUNS (Project PGI 24/Q026) from Argenitna. F.N. also thanks the CIC-PBA for a doctoral fellowship. The authors also thanks Dr. Franciso Alonso and the Servicios Técnicos de Investigación of the University of Alicante (Spain) for TEM analysis.

\section{References}

1. (a) Nicolaou, K. C.; Yang, Z.; Liu, J. J.; Ueno, H.; Nantermet, P. G.; Guy, R. K.; Claiborn, C. F.; Renaud, J.; Couladouros, E. A.; Paulvannan, K.; Sorensen, E. J. J. Am. Chem. Soc. 1995, 117, 624. (b) Mehta, G.; Singh, V. Chem. Rev. 1999, 99, 881. (c) Kammermeier, B.; Beck, G.; Jacobi, D.; Jendralla, H. Angew. Chem. Int. Ed. Engl. 1994, 33, 685. (d) McMurry, J. E.; Dushin, R. G. J. Am. Chem. Soc. 1989, 111, 8928. (e) Corey, E. J.; Kania, R. S. Tetrahedron Lett. 1998, 39, 741. (f) Ephritikhine, M.; Villiers, C. Modern Carbonyl Olefination; Takeda, T., Ed.; Wiley-VCH: Weinheim, 2004; p 223. (g) Fürstner, A.; Ernst, A.; Krause, H.; Ptock, A. Tetrahedron 1996, 52, 7239. (h) Ladipo, F. T. Curr. Org. Chem. 2006, 10,965 . 
2. Mukaiyama, T.; Sato, T.; Hanna, J. Chem Lett. 1973, 1041.

3. McMurry, J. E.; Fleming, M. P. J. Am. Chem. Soc. 1974, 96, 4708.

4. For reviews on this subject, see: (a) Chatterjee, A.; Joshi, N. N. Tetrahedron 2006, 62, 12137. (b) Hirao, T. Top. Curr. Chem. 2007, 279, 53. See also: (c) Yang, Y.-S.; Shen, Z.-L.; Loh, T.-P. Org. Lett. 2009, 11, 2213. (d) Sun, J.; Dai, Z.; Li, C.; Pan, X.; Zhu, C. J. Organomet. Chem. 2009, 694, 3219. (e) Halterman, R. L.; Porterfield, J. P.; Mekala, S. Tetrahedron Lett. 2009, 50, 7172 and references cited therein. (f) Groth, U.; Jung, M.; Lang, S.; Schuppler, T. Tetrahedron Lett. 2009, 50, 152. (g) Aspinall, H. C.; Greeves, N.; Hin, S. L. F. Tetrahedron Lett. 2010, 51, 1558. (h) Okamoto, S.; He, J.-Q.; Ohno, C.; Oh-iwa, Y.; Kawaguchi, Y. Tetrahedron Lett. 2010, 51, 387.

5. (a) McMurry, J. E. Chem. Rev. 1989, 89, 1513. (b) Kahn, B. E.; Rieke, R. D. Chem. Rev. 1988, 88, 733. (c) Ephritikhine, M. Chem. Commun. 1998, 2549. (d) Fürstner, A.; Bogdanovic, B. Angew. Chem. Int. Ed. 1996, 35, 2442. (e) Lenoir, D. Synthesis 1989, 883. (f) Rele, S. M.; Nayak, S. K.; Chattopadhyay, S. Tetrahedron 2008, 64, 7225 and references cited therein.

6. (a) Moreno-Mañas, M.; Pleixats, R. Acc. Chem. Res. 2003, 36, 638. (b) Narayanan, R.; ElSayed, M. A. J. Am. Chem. Soc. 2003, 125, 8340. (c) Reetz, M. T.; deVries, J. G. Chem. Commun. 2004, 1559. (d) Astruc, D.; Lu, F.; Aranzaes, J. R. Angew. Chem. Int. Ed. 2005, 44,7852 .

7. Aiken, J. D.; Finke, R. G. J. Mol. Catal. A: Chem. 1999, 145, 1.

8. (a) Cintas, P. Activated Metals in Organic Synthesis; CRC: Boca Raton, 1996. (b) Lectka, T. Active Metal - Preparation, Characterization, Applications; Fürstner, A., Ed.; VCH: Weinheim, 1996; pp 85-131. (c) Bradey, J. S.; Schmid, G. Nanopartciles: From Theory to Application; Schmid, G., Ed; Wiley-VCH: Weinheim, 2005; pp 185-199.

9. Raffa, P.; Evangelisti, C.; Vitulli, G.; Salvadori, P. Tetrahedron Lett. 2008, 49, 3221.

10. (a) Moglie, Y.; Alonso, F.; Vitale, C.; Yus, M.; Radivoy, G. Tetrahedron 2006, 62, 2812. (b) Moglie, Y.; Alonso, F.; Vitale, C.; Yus, M.; Radivoy, G. Appl. Catal. A: Gen. 2006, 313, 94. (d) Alonso, F.; Vitale, C.; Radivoy, G.; Yus, M. Synthesis 2003, 443. (e) Radivoy, G.; Alonso, F.; Moglie, Y.; Vitale, C.; Yus, M. Tetrahedron 2005, 61, 3859. (f) Nador, F.; Vitale, C.; Moglie, Y.; Yus, M.; Alonso, F.; Radivoy, G. Tetrahedron 2010, 66, 4318.

11. (a) Moglie, Y.; Vitale, C.; Radivoy, G. Tetrahedron Lett. 2008, 49, 1828. (b) Nador, F.; Fortunato, L.; Moglie, Y.; Vitale, C.; Radivoy, G. Synthesis 2009, 4027. (c) Moglie, Y.; Mascaró, E.; Nador, F.; Vitale, C.; Radivoy, G. Synth. Commun. 2008, 38, 3861.

12. Carbonyl compounds bearing an appropriately placed chelating group have demonstrated enhanced reactivity in pinacol coupling and alkylation reactions: (a) Freudenberger, J. H.; Konradi, A. W.; Pedersen, S. F. J. Am. Chem. Soc. 1989, 111, 8014. (b) Reetz, M. T.; Maus, S. Tetrahedron 1987, 43, 101.

13. Perrin, D. D.; Amarego, W. L. F. Purification of Laboratory Chemicals; Pergamon Press: Oxford, 1988. 
14. (a) Benkeser, R. A.; DeTalvo, W.; Darling, D. J. Org. Chem. 1979, 44, 225. (b) Vogel, A. I. A Text-Book of Practical Organic Chemistry; Longman Press: London, 1974; p 252. (c) Mascareñas, J. L.; Mouriño, A.; Castedo, L. J. Org. Chem. 1986, 51, 1269.

15. Ryu, I.; Ando, M.; Ogawa, A.; Murai, S.; Sonoda, N. J. Am. Chem. Soc. 1983, 105, 7192.

16. Katrizky, A. R.; Huang, Z.; Fang, Y.; Prakash, I. J. Org. Chem. 1999, 64, 2124.

17. Wang, C.; Yuanjiang, P.; Wu, A. Tetrahedron 2007, 63, 429.

18. Li, C.-J.; Meng, Y.; Yi, X.-H.; Ma, J.; Chan, T.-H. J. Org. Chem. 1998, 63, 7498.

19. (a) Fürstner, A.; Hupperts, A. J. Am. Chem. Soc. 1995, 117, 4468. (b) Hoffman, W. D.; McEwen, W. E.; Kleinberg, J. Tetrahedron, 1959, 5, 293.

20. Batsanov, A. S.; Bruce, J. I.; Ganesh, T.; Low, P. J.; Kataky, R.; Puschmann, H.; Steel, P. G. J. Chem. Soc., Perkin Trans. 1 2002, 932.

21. Talukdar, S.; Nayak, S. K.; Banerji, A. J. Org. Chem. 1998, 63, 4925.

22. Gordillo, A.; de Jesús, E.; López-Mardomingo, C. Chem. Commun. 2007, 4056.

23. Shostakovskii, V. M.; Samoilova, M. Y.; Nefedov, O. M. Russ. Chem. Bull. 1973, 22, 2330.

24. Balu, N.; Nayak, S. K.; Banerji, A. J. Am. Chem. Soc. 1996, 118, 5932.

25. Cristau, H.-J.; Grenier, J.; Torreilles, E. Phosphorus Sulfur Silicon Relat. Elem. 1994, 89, 163.

26. Baumstark, A. L.; McCloskey, C. J.; Witt, K. E. J. Org. Chem. 1978, 43, 3609.

27. Marvell, E. N.; Caple, G.; Delphey, C.; Platt, J.; Polston, N.; Tashiro, J. Tetrahedron 1973, 29, 3797.

28. Cho, Y. L.; Uh, H.; Chang, S.-Y.; Chang, H.-Y.; Choi, M.-G.; Shin, I.; Jeong, K.-S. J. Am. Chem. Soc. 2001, 123, 1258.

29. Xu, X.; Hirao, T. J. Org. Chem. 2005, 70, 8594. 